\title{
Complete sequences of KPC-2-encoding plasmid p628-KPC and CTX-M-55-encoding p628-CTXM coexisted in Klebsiella pneumoniae
}

OPEN ACCESS

Edited by:

Patrick Rik Butaye,

Ghent University, Belgium

Reviewed by:

Yoshikazu Ishii,

Toho University School of Medicine,

Japan

Aurora García-Fernández,

Istituto Superiore di Sanità, Italy

*Correspondence: Hong Du,

Department of Clinical Laboratory, The Second Affiliated Hospital of Soochow University, No. 181, Sanxiang Road, Suzhou, Jiangsu 215004, China

hong_du@126.com;

Dongsheng Zhou,

State Key Laboratory of Pathogen and

Biosecurity, Beijing Institute of Microbiology and Epidemiology, No. 20, Dongda Street, Fengtai

District, Beijing 100071, China dongshengzhou1977@gmail.com

Specialty section:

This article was submitted to Antimicrobials, Resistance and

Chemotherapy,

a section of the journal

Frontiers in Microbiology

Received: 16 May 2015

Accepted: 31 July 2015

Published: 19 August 2015

Citation:

Wang L, Fang H, Feng J, Yin Z, Xie X, Zhu X, Wang J, Chen W, Yang $R$, Du $H$ and Zhou D (2015) Complete sequences of KPC-2-encoding plasmid p628-KPC and

CTX-M-55-encoding p628-CTXM coexisted in Klebsiella pneumoniae.

Front. Microbiol. 6:838

doi: 10.3389/fmicb.2015.00838

\author{
Li Wang ${ }^{1}$, Haihong Fang ${ }^{2}$, Jiao Feng ${ }^{2}$, Zhe Yin ${ }^{2}$, Xiaofang Xie ${ }^{3}$, Xueming Zhu ${ }^{3}$, \\ Jie Wang ${ }^{2}$, Weijun Chen ${ }^{4}$, Ruisheng Yang ${ }^{1}$, Hong Du ${ }^{3 *}$ and Dongsheng Zhou ${ }^{2 *}$ \\ 'Department of Clinical Laboratory, The First Hospital Affiliated to Henan University, Kaifeng, China, ${ }^{2}$ State Key Laboratory of \\ Pathogen and Biosecurity, Beijing Institute of Microbiology and Epidemiology, Beijing, China, ${ }^{3}$ Department of Clinical \\ Laboratory, The Second Affiliated Hospital of Soochow University, Suzhou, China, ${ }^{4}$ Beijing Institute of Genomics, Chinese \\ Academy of Sciences, Beijing, China
}

A carbapenem-resistant Klebsiella pneumoniae strain 628 was isolated from a human case of intracranial infection in a Chinese teaching hospital. Strain 628 produces KPC-2 and CTX-M-55 encoded by two different conjugative plasmids, i.e., the IncFII $I_{K}$ plasmid p628-KPC and the Incl1 plasmid p628-CTXM respectively. bla KPC-2 is captured by a Tn1722-based unit transposon with a linear structure. $\Delta$ Tn3-ISKpn27-b/aKPC-2-

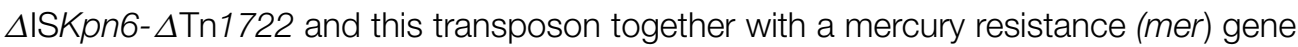
locus constitutes a $34 \mathrm{~kb}$ acquired drug-resistance region. bla $\mathrm{KPC}_{-2}$ has two transcription starts (nucleotides $\mathrm{G}$ and $\mathrm{C}$ located at 39 and $250 \mathrm{bp}$ upstream of its coding region respectively) which correspond to two promoters, i.e., the intrinsic $\mathrm{P} 1$ and the upstream ISKpn27/Tn3-provided P2 with the core -35/-10 elements TAATCC/TTACAT and TTGACA/AATAAT respectively. bla $\mathrm{CTX}-\mathrm{M}-55$ is mobilized in an ISECp1-bla $\triangle$ orf477 transposition unit and appears to be the sole drug-resistant determinant in p628-CTXM. bla at $116 \mathrm{bp}$ upstream of its coding region) corresponding to the ISEcP1-provided P1 promoter with the core $-35 /-10$ element TTGAAATACAAT. All the above detected promoters display a characteristic of constitutive expression. Coexistence of bla KPC and bla $\mathrm{C}_{\mathrm{CT}-\mathrm{M}}$ in $K$. pneumoniae has been reported many times but this is the first report to gain deep insights into genetic platforms, promoters, and expression of the two coexisting bla genes with determination of entire nucleotide sequences of the two corresponding plasmids.

Keywords: Klebsiella pneumoniae, KPC-2, CTX-M-55, p628-KPC, p628-CTXM, promoter

\section{Introduction}

KPC-producing Klebsiella pneumoniae has spread worldwide and became an emerging pathogen with serious clinical and infection control implications (Tzouvelekis et al., 2012; MunozPrice et al., 2013). Coexistence of bla $a_{\mathrm{KPC}}$ and bla ${ }_{\mathrm{CTX}-\mathrm{M}}$ in K. pneumoniae has been reported in several countries, such as bla $a_{\mathrm{KPC}-2} / b l_{\mathrm{CTX}-\mathrm{M}-1}$ group, bla $a_{\mathrm{KPC}-2} / b a_{\mathrm{CTX}-\mathrm{M}-2}$ group, and 
$b l a_{\mathrm{KPC}-2} / b l a_{\mathrm{CTX}-\mathrm{M}-8}$ group in Brazil (Peirano et al., 2009), bla $a_{\mathrm{KPC}-2} / b l a_{\mathrm{CTX}-\mathrm{M}-10}, \quad b l a_{\mathrm{KPC}-2} / b l a_{\mathrm{CTX}-\mathrm{M}-15}$, and $b l a_{\mathrm{KPC}-3} / b l a_{\mathrm{CTX}-\mathrm{M}-2}$ in Israel (Leavitt et al., 2007, 2010), $b l a_{\mathrm{KPC}-2} / b l a_{\mathrm{CTX}-\mathrm{M}-14}$ in China (Cai et al., 2008), and $b l a_{\mathrm{KPC}-2} / b l a_{\mathrm{CTX}-\mathrm{M}-15}$ in Greece (Souli et al., 2010). However, all these studies are confined to PCR detection and sequencing of bla genes, lacking deeper characterization of mechanisms of drug resistance. This study describes co-production of KPC-2 and CTX-M-55 in a clinical K. pneumoniae strain 628 from China. The bla $a_{\mathrm{KPC}-2}$ and $b l a_{\mathrm{CTX}-\mathrm{M}-55}$ genes are encoded by two different conjugative plasmids, p628-KPC and p628-CTXM respectively. The complete nucleotide sequences of p628-KPC and p628-CTXM are determined and then compared with other genetically closely related plasmids to gain deep insights into genetic structures of relevant plasmids and resistance gene loci. In addition, the promoters and their expression characteristics of these two plasmid-borne bla genes are dissected experimentally.

\section{Materials and Methods}

\section{Bacterial Strains and Identification}

K. pneumoniae strain 628 was isolated from the cerebrospinal fluid specimen of a 64-year-old male with intracranial infection in a Chinese teaching hospital in October 2010. Bacterial species identification was performed using Bruker MALDI Biotyper (Bruker Daltonics, Bremen, Germany) and 16s rRNA gene sequencing (Frank et al., 2008). The major carbapenemase and extended-spectrum beta-lactamase (ESBL) genes were detected by PCR, followed by sequencing on an ABI Sequencer (Applied Biosystems, Foster City, CA, USA) (Chen et al., 2015). Bacterial antimicrobial susceptibility was tested by using VITEK 2 and judged by CLSI standard (CLSI, 2012).

\section{Plasmid Transfer}

Plasmid conjugal transfer experiments were carried out with Escherichia coli EC600 ( $\mathrm{LacZ}^{-}, \mathrm{Nal}^{\mathrm{R}}$, Rif ${ }^{\mathrm{R}}$ ) being used as recipient and strain 628 as donor. Three milliliter of overnight culture of each of donor and recipient bacteria were mixed together, harvested and resuspended in $80 \mu \mathrm{l}$ of Brain Heart Infusion broth (BD Biosciences, San Jose, CA, USA). The mixture was spotted on a $1 \mathrm{~cm}^{2}$ filter membrane that was placed on Brain Heart Infusion agar (BD Biosciences, San Jose, CA, USA) plate, and then incubated for mating at $37^{\circ} \mathrm{C}$ for 12 to $18 \mathrm{~h}$. Bacteria were washed from filter membrane and spotted on Muller-Hinton agar (BD Biosciences, San Jose, CA, USA) plate containing $1000 \mathrm{mg} / \mathrm{L}$ rifampin (Merck, Darmstadt, Germany) and $200 \mathrm{mg} / \mathrm{L}$ ampicillin (Merck, Darmstadt, Germany) for

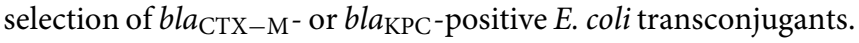

\section{Determination of Plasmid DNA Sequence}

Plasmid DNA was isolated from the cell culture of E. coli transconjugant using Qiagen large construct kit (Qiagen, Hilden, Germany) and then sequenced by using whole-genome shotgun strategy in combination with Illumina HiSeq 2500 (Illumina, San Diego, CA, USA) sequencing technology. The contigs were assembled with Velvet and the gaps were filled through combinatorial PCR and Sanger Sequencing on ABI 3730
Sequencer. The genes were predicted with GeneMarkS ${ }^{\mathrm{TM}}$ and further annotated by BLASTP and BLASTN against UniProt and NR databases.

\section{RNA Isolation and Primer Extension Assay}

Bacteria were cultured overnight in Mueller-Hinton broth (BD Biosciences, San Jose, CA, USA). Total RNAs were extracted from harvested bacterial cells using TRIzol Reagent (Life Technologies, Carlsbad, CA, USA). RNA quality was monitored by agarose gel electrophoresis, and RNA quantity was determined by spectrophotometry. Each of the $[\gamma-$ ${ }^{32} \mathrm{P}$ ] ATP end-labeled primers GCTCAGTGGAACGAAAAC, AGCCGCCAAAGTCCTGTTCG, and CATGGGATTCCTTATT CTG, which corresponded to $b l a_{\mathrm{KPC}-2}$ promoter $\mathrm{P} 2$, $b l a_{\mathrm{KPC}-2}$ promoter $\mathrm{P} 1$, and $b l a_{\mathrm{CTX}-\mathrm{M}-55}$ promoter $\mathrm{P} 1$ respectively, was annealed with total RNA sample for primer extension assay as described previously (Zhang et al., 2011). For different cell cultures in a single experiment, equal amounts of total RNA were used as starting materials. The corresponding end-labeled primers were also used for sequencing the PCR amplicons generated by the primer pairs TCAGCGACATCGTCAACC/GGTCGTGTTTCCCTTTAGCC, TCAGGTGGCACTTTTCGG/GGTCGTGTTTCCCTTTAGCC, and AGACCTTTCGTTTGAAGTATG/AGCTTATTCATCGCC ACGTT for $b l a_{\mathrm{KPC}-2}$ promoter $\mathrm{P} 2, b l a_{\mathrm{KPC}-2}$ promoter P1, and $b l a_{\mathrm{CTX}-\mathrm{M}-55}$ promoter $\mathrm{P} 1$ respectively. DNA sequencing was carried out using AccuPower \& Top DNA Sequencing Kit (Bioneer, Daejeon, Korea). Primer extension products and sequencing materials were analyzed on $8 \mathrm{M}$ urea-6\% polyacrylamide gel electrophoresis. Radioactive species were detected by autoradiography.

\section{Nucleotide Sequence Accession Numbers}

The complete sequences of plasmids p628-KPC and p628-CTXM were submitted to GenBank under accession numbers KP987218 and KP987217 respectively.

\section{Results and Discussion}

\section{Characterization of $K$. pneumoniae Strain $\mathbf{6 2 8}$}

Strain 628 harbors bla $a_{\mathrm{KPC}-2}, b l a_{\mathrm{CTX}-\mathrm{M}-55}, b l a_{S H V}$, and bla $a_{T E M}$. $b l a_{\mathrm{KPC}-2}$ and $b l a_{\mathrm{CTX}-\mathrm{M}-55}$ are located plasmids p628-KPC and p628-CTXM respectively. Conjugative transfer of p628-KPC or p628-CTXM into EC600 generates the transconjugant 628-KPCEC600 $\left(b l a_{\mathrm{KPC}-2}^{+}, b l a_{\mathrm{CTX}-\mathrm{M}-55}^{-}, b l a_{\mathrm{SHV}}^{-}\right.$, and $\left.b l a_{\mathrm{TEM}}^{-}\right)$or 628 CTXM-EC600 (bla $a_{\mathrm{KPC}-2}^{-}, b l a_{\mathrm{CTX}-\mathrm{M}-55}^{+}, b l a_{\mathrm{SHV}}^{-}$, and $\left.b l a_{\mathrm{TEM}}^{-}\right)$ respectively. All of 628, 628-KPC-EC600 and 628-CTXM-EC600 are resistant to ampicillin, ampicillin/sulbactam, penicillin, monobactam, and cephalosporins tested (Table 1). 628 and 628-KPC-EC600 (but not 628-CTXM-EC600) are resistant to piperacillin/tazobactam. 628 and 628-KPC-EC600 (but not 628CTXM-EC600) are carbapenem-resistant.

\section{Complete Nucleotide Sequence of p628-KPC}

The entire nucleotide sequence of p628-KPC is $105,008 \mathrm{bp}$ in length, forming a circular plasmid with an average $\mathrm{G}+\mathrm{C}$ content of 53.22 and a total of 127 open reading frames (ORFs) annotated 
TABLE 1 | Antimicrobial drug susceptibility profiles.

\begin{tabular}{|c|c|c|c|c|}
\hline Antibiotics & \multicolumn{4}{|c|}{ MIC (mg/L)/antimicrobial susceptibility } \\
\hline Ampicillin/sulbactam & $\geq 32 / \mathrm{R}$ & $\geq 32 / \mathrm{R}$ & $\geq 32 / \mathrm{R}$ & $4 / \mathrm{S}$ \\
\hline Piperacillin & $\geq 128 / \mathrm{R}$ & $\geq 128 / \mathrm{R}$ & $\geq 128 / R$ & $\leq 4 / \mathrm{S}$ \\
\hline Piperacillin/tazobactam & $\geq 128 / R$ & $\geq 128 / \mathrm{R}$ & $\leq 4 / \mathrm{S}$ & $\leq 4 / \mathrm{S}$ \\
\hline Cefuroxime sodium & $\geq 64 / \mathrm{R}$ & $\geq 64 / \mathrm{R}$ & $\geq 64 / \mathrm{R}$ & 16/I \\
\hline Cefuroxime axetil & $\geq 64 / \mathrm{R}$ & $\geq 64 / \mathrm{R}$ & $\geq 64 / \mathrm{R}$ & 16/I \\
\hline Ceftriaxone & $\geq 64 / \mathrm{R}$ & $\geq 64 / \mathrm{R}$ & $\geq 64 / \mathrm{R}$ & $\leq 1 / \mathrm{S}$ \\
\hline Ceftazidime & $\geq 64 / \mathrm{R}$ & $16 / \mathrm{R}$ & $\geq 64 / \mathrm{R}$ & $\leq 1 / \mathrm{S}$ \\
\hline Imipenem & $\geq 16 / \mathrm{R}$ & $\geq 16 / R$ & $\leq 1 / \mathrm{S}$ & $\leq 1 / \mathrm{S}$ \\
\hline Macrodantin & $\geq 512 / \mathrm{R}$ & $\leq 16 / \mathrm{S}$ & $\leq 16 / \mathrm{S}$ & $\leq 16 / \mathrm{S}$ \\
\hline Amikacin & $\leq 2 / \mathrm{S}$ & $\leq 2 / \mathrm{S}$ & $\leq 2 / \mathrm{S}$ & $\leq 2 / \mathrm{S}$ \\
\hline Tobramycin & $\leq 1 / \mathrm{S}$ & $\leq 1 / \mathrm{S}$ & $\leq 1 / \mathrm{s}$ & $\leq 1 / \mathrm{s}$ \\
\hline Trimethoprim/sulfamethoxazole & $40 / \mathrm{s}$ & $\leq 20 / \mathrm{s}$ & $\leq 20 / \mathrm{s}$ & $\leq 20 / \mathrm{s}$ \\
\hline
\end{tabular}
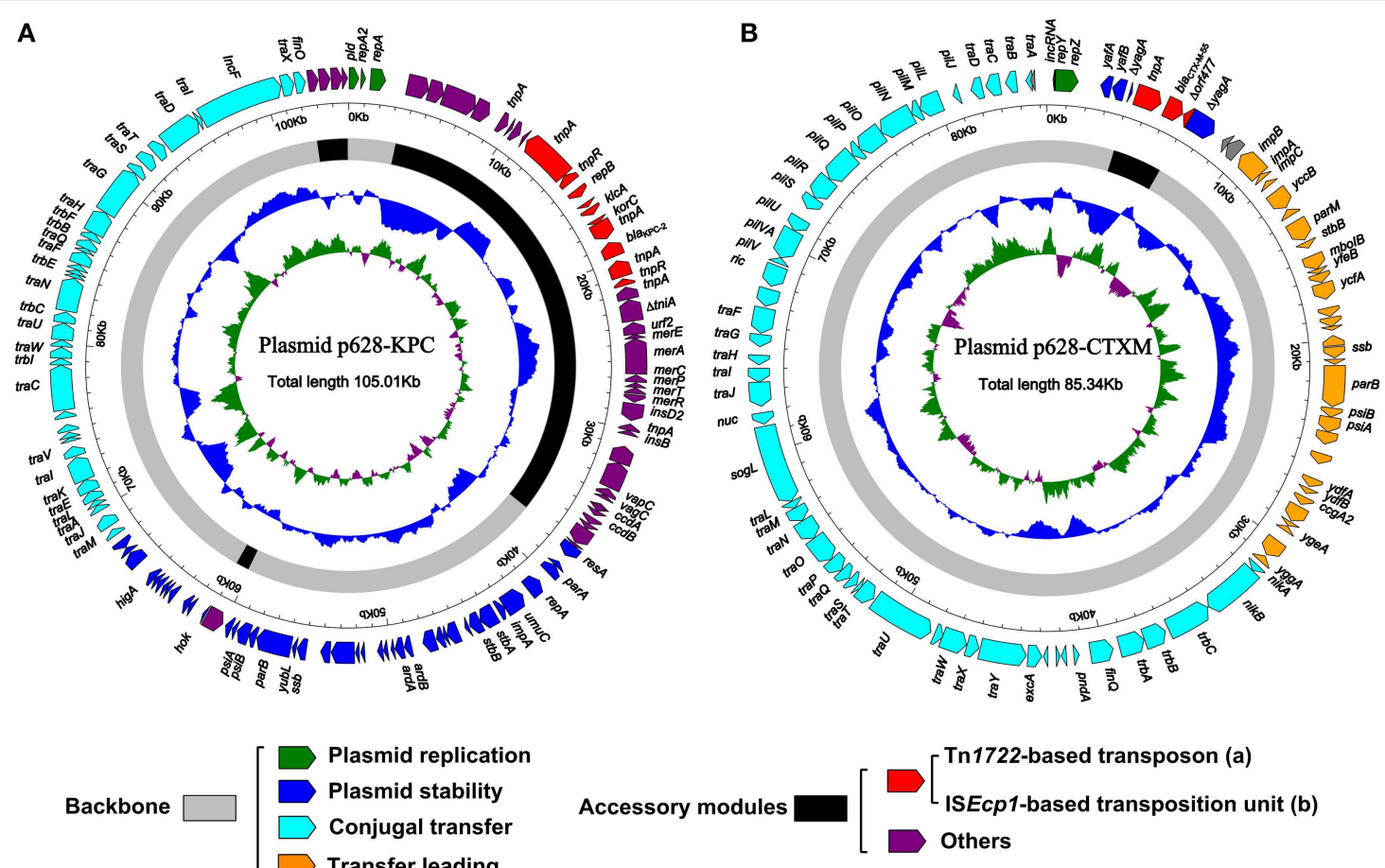

FIGURE 1 | Schematic maps of p628-KPC (A) and p628-CTXM (B). Genes are denoted by arrows and colored based on gene function classification. The innermost circle presents GC-Skew $[(G-C) /(G+C)]$ with a window size of $500 \mathrm{bp}$ and a step size of $20 \mathrm{bp}$. The blue circle presents GC content. Shown also are backbone and accessory module regions.
(Figure 1A). p628-KPC belongs to the IncFII $_{\mathrm{K}}$ incompatibility group and harbors IncFII $_{\mathrm{K}}$ repA and the second IncFIB-like repA2, both of which encode replication initiation proteins.
The p628-KPC backbone, 67,515 bp in length, is composed of DNA regions for plasmid replication (repA and repA2) and stability ( $p a r A B, s t b A B, s s b$, etc), and conjugal transfer (tra, trb, 
A

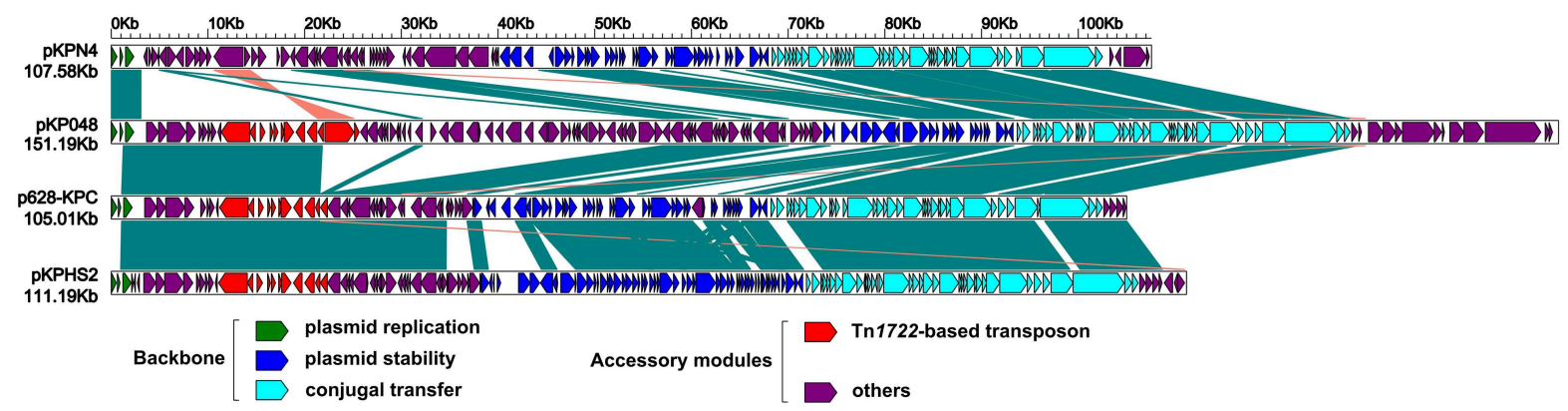

B

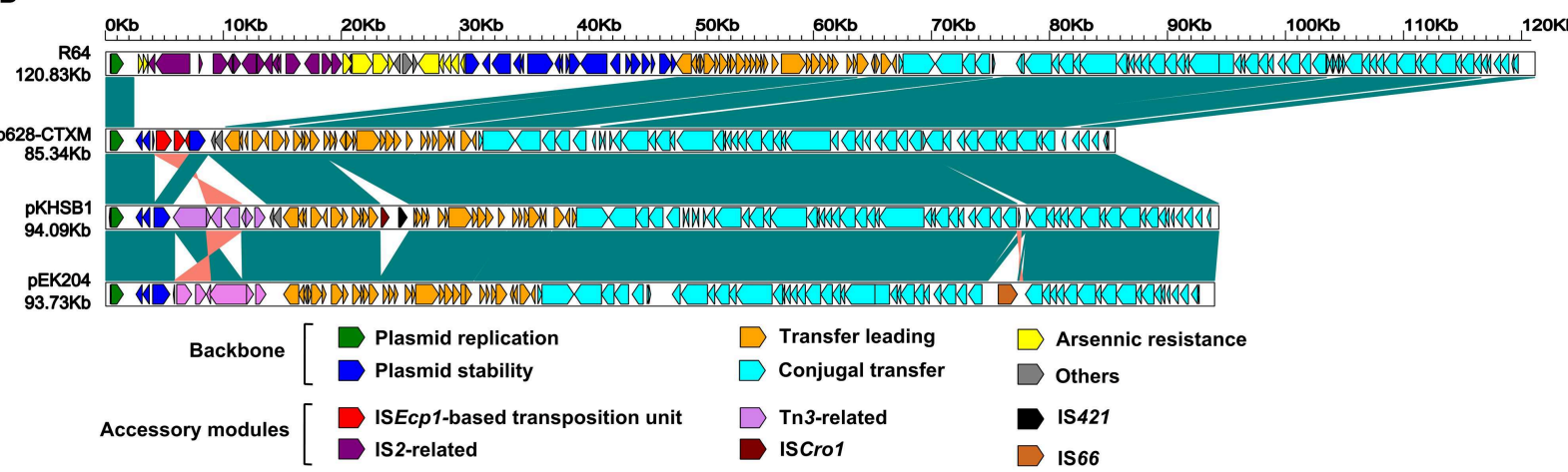

FIGURE 2 | Linear comparison of sequenced plasmids. Genes are denoted by arrows and colored based on gene function classification. Shading regions denote regions of homology (>98\% nucleotide similarity). Included are p628-KPC (A) and p628-CTXM (B) and their closely related plasmids.

TABLE 2 | Genetic surroundings of bla $\mathrm{KPC}-2$ from China.

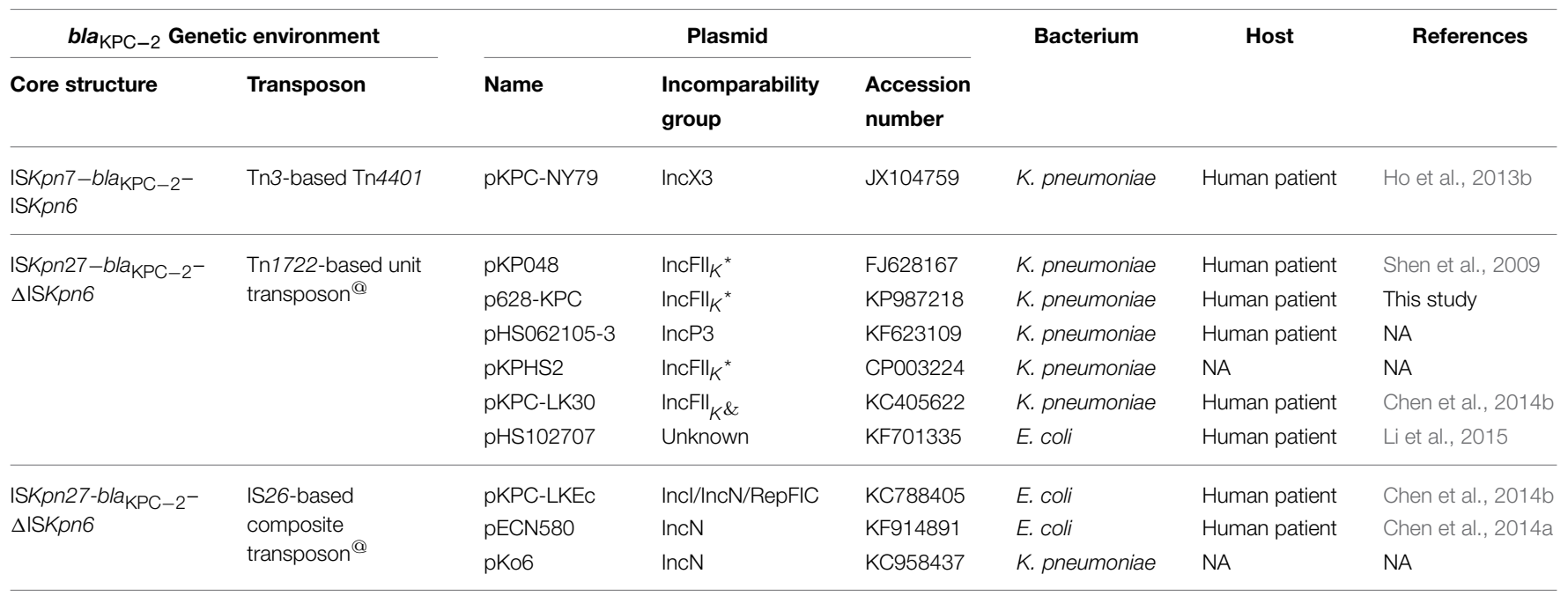

Included are all the blaKPC-carrying plasmids with determined genome sequences from China.

@ See reference (Roberts et al., 2008) for classification of transposons.

*In addition to the IncFII repA, the plasmid contains the second IncFIB-like repA2.

$\&$ This plasmid harbors a repB putative replication initiation region but, surprisingly, lacks the IncFII repA.

etc), which show $>98 \%$ sequence identity to the corresponding regions of the IncFII $\mathrm{K}$ plasmids pKPN4 (GenBank accession number CP000649), pKP048 (Jiang et al., 2010), and pKPHS2 (CP003224) (Figure 2A). The overall structure of p628-KPC is most similar to that of pKPHS2 (91\% query coverage and $98 \%$ maximum nucleotide identity) (Figure 2A). pKPN4 is recovered from clinical K. pneumoniae MGH 78578 and represents the reference $\mathrm{IncFII}_{\mathrm{K}}$ plasmid, carrying bla $\mathrm{SHV}_{\mathrm{SH}}$ (cephalosporin 


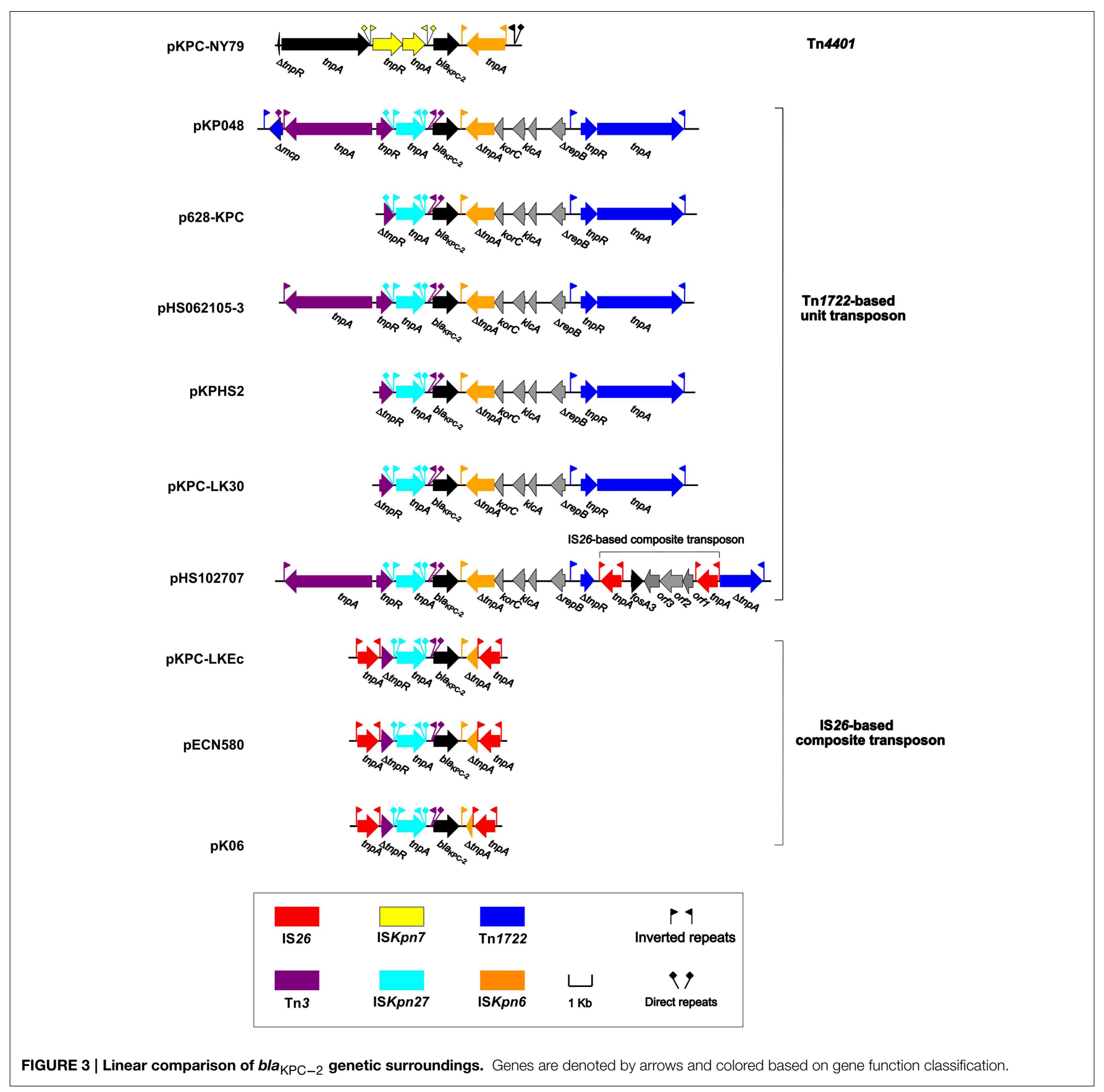

resistance), and $\operatorname{aac}\left(6^{\prime}\right)$ and $\operatorname{aad} A$ (aminoglycoside resistance). pKP048 and pKPHS2 are from two KPC-2-producing clinical $K$. pneumoniae isolates from China.

As shown in Figures 1A,2A, p628-KPC contains three distinct accessory modules: a $34 \mathrm{~kb}$ drug-resistance region, a $1038 \mathrm{bp}$ ISKpn28-based element, and a 2302 bp region of unknown function [identical sequences can be found in bla $a_{\mathrm{KPC}-2 \text {-carrying }}$ plasmid pKPCAPSS (KP008371) and qnrS1-harboring pE66An (HF545433)]. The $34 \mathrm{~kb}$ region harbors two drug-resistance loci, the mer locus (mercury resistance) and the bla $a_{\mathrm{KPC}-2}$ locus, and it is almost the same as the counterpart of pKPHS2
(Figure 2A). A $71 \mathrm{~kb}$ multi-drug-resistance region in pKP048 (Jiang et al., 2010) is composed of the $34 \mathrm{~kb}$ region of p628KPC and the extra part (carrying $b l a_{\mathrm{DHA}-1}, q n r B 4$, and armA encoding resistance to cephalosporins, fluoroquinolones, and aminoglycosides respectively) absent from p628-KPC (Figure 2A).

\section{Complete Nucleotide Sequence of p628-CTXM}

The p628-CTXM genome consists of an 85,338 bp circular DNA molecule with an average $\mathrm{G}+\mathrm{C}$ content of 49.71 and harbors a total of 92 ORFs annotated (Figure 1B). p628-KPC belongs 


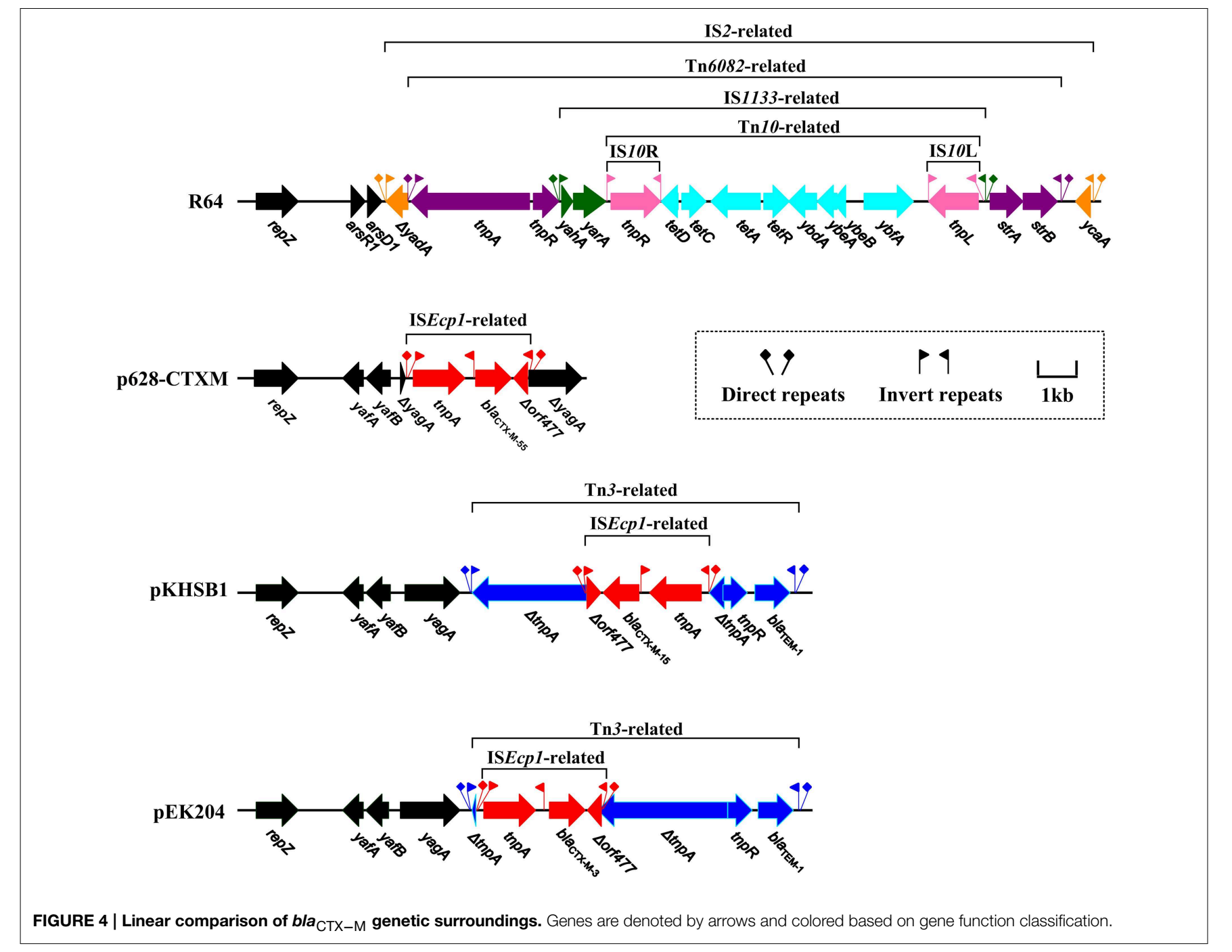

to the IncI1 incompatibility group expressing the replication initiation protein RepZ. The p628-CTXM backbone, 82,357 bp in length, contains DNA regions for plasmid replication (repY, repZ, and inc), conjugal transfer (tra, trb, pil, etc) and transfer leading (imp, yfa to $y f h, y g a$ to $y g g$, etc), which show $>98 \%$ sequence identity to the corresponding regions of the IncI1 plasmids R64 from Salmonella enterica serovar Typhimurium (Sampei et al., 2010), pKHSB1 from Shigella sonnei (Holt et al., 2013) and pEK204 from E. coli O25:H4-ST131 clone (Woodford et al., 2009) (Figure 2B). Another backbone component is the plasmid stability region, composed of three genes yaf $A$, yaf $B$, and yagA, which is highly conserved among p628-CTXM, pKHSB1, and pEK204; by contrast, the corresponding segment of R64 is a $17.8 \mathrm{~kb}$ region which harbors at least 18 genes and especially include those encoding site-specific recombination (resD and yefA) and partition (par $A B$ ) of replicated DNA into daughter cells during cell division (Sampei et al., 2010) (Figure 2B).

R64 carries a single accessory module, a $17 \mathrm{~kb}$ IS2based transposon, which interrupts arsA1 (a member of the arsR1-arsD1-arsA1-arsB-arsC operon) (Sampei et al., 2010).
p628-CTXM harbors a single accessory module, a $2980 \mathrm{bp}$ ISEcp1-related element, which interrupts yagA (a member of the plasmid stability region) (Figures 1B, 2B). Two distinct Tn3-related elements, 7935 and 8014 bp in length, are inserted downstream of yagA in pKHSB1 and pEK204 respectively. There are still additional accessory modules including ISCro1 and IS421 for pKHSB1, and IS66 for pEK204.

\section{Genetic Surroundings of bla $a_{\mathrm{KPC}-2}$}

As characterized in European and American countries, the $b l a_{\mathrm{KPC}}$ genes are located in a Tn3-family transposon named Tn4401, which is present on a wide variety of plasmids varying in size, structure and replicon (Naas et al., 2008; Kitchel et al., 2009, 2010; Chen et al., 2012; Bryant et al., 2013; Chmelnitsky et al., 2014). At least eight isoforms of Tn4401 have been named, i.e., Tn4401a to Tn4401g and a separate Tn4401d (Table S1 in Supplementary Material). Several unnamed Tn4401 isoforms have been also reported recently (Cuzon et al., 2011; Li et al., 2011; Ho et al., 2013b; Naas et al., 2013; Perez-Chaparro et al., 2014). Tn $4401 b$ is considered as the prototype one, and the other 


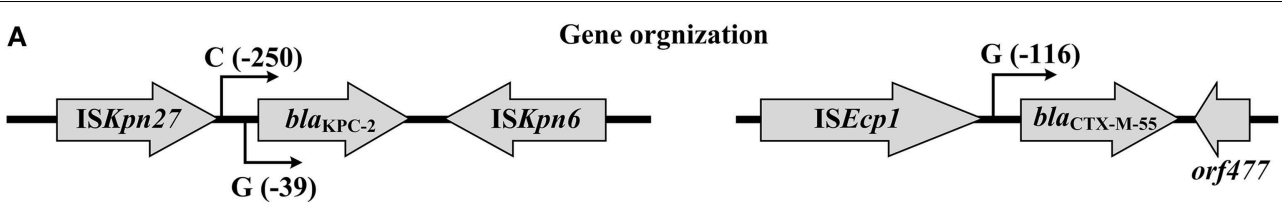

B
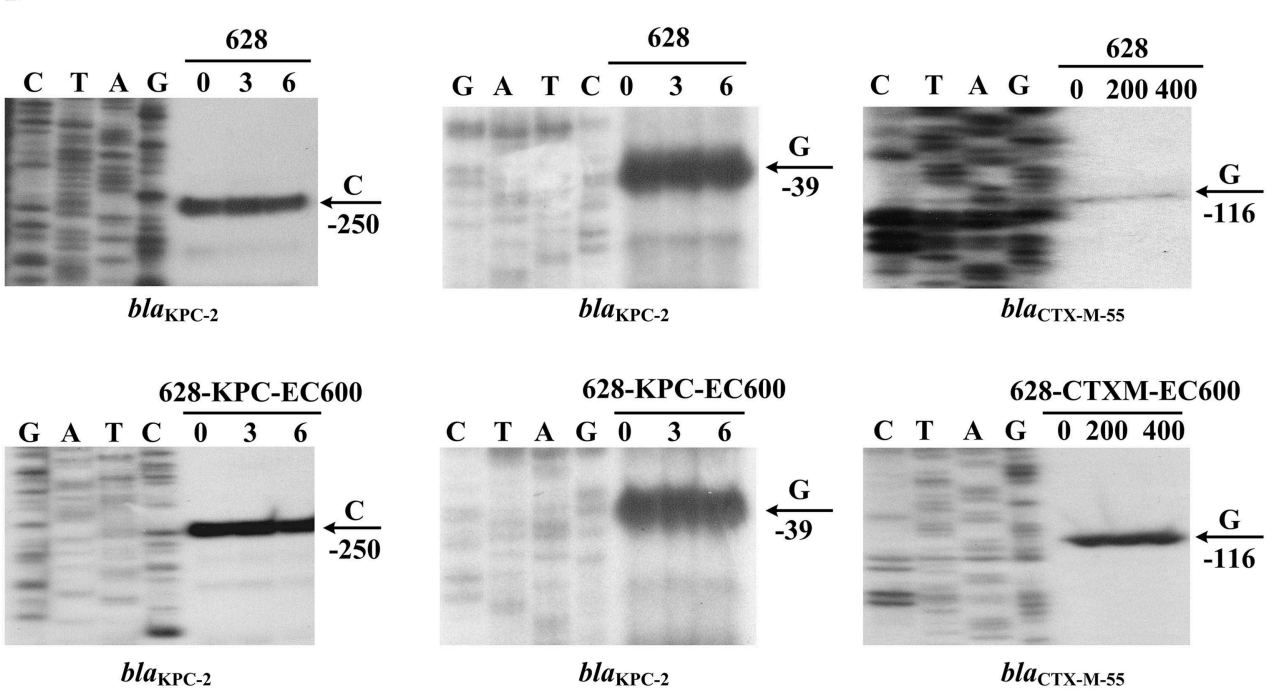

FIGURE 5 | Organization and expression of bla genes. (A) Gene organization. Boxed arrows stand for length/direction of indicated genes. Broken-line arrows represent transcription starts for indicated bla genes. (B) Primer extension. Primer extension assay of the RNA transcript of each bla gene was performed for strain 628 cultured with addition of increasing amounts of imipenem or ampicillin. Lanes C, T, A, and G represent Sanger sequencing reactions. Lanes 0,3 , and 6 stand for 0,3 , and $6 \mathrm{mg} / \mathrm{L}$ imipenem. Lanes 0, 200, and 400 stand for 0, 200, and $400 \mathrm{mg} / \mathrm{L}$ ampicillin. Transcription start of each bla gene is indicated by arrow with nucleotide, and minus number under arrow indicates nucleotide position upstream of indicated bla gene. Representative data from at least two independent biological replicates are shown. isoforms result from occurrence of distinct deletion or insertion events at different sites.

As shown in Table 2 and Figure 3, the bla $a_{\mathrm{KPC}-2}$ genetic environments from China can be assigned into three main categories: Tn4401 with the ISKpn7-bla $a_{\mathrm{KPC}-2-I S K p n 6}$ core structure (pKPC-NY79), the Tn1722-based unit transposons

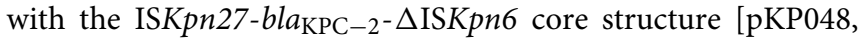
p628-KPC, pHS062105-3, pKPHS2, pKPC-LK30, and pHS102707; ISKpn27 is initially named in the ISfinder database (Siguier et al., 2006)], and the IS26-based composite transposons

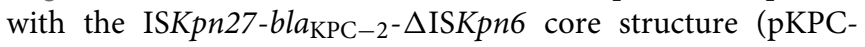
LKEc, pECN580, and pKo6). The Tn4401 of pKPC-NY79 is a novel isoform of Tn4401a with $\operatorname{tn} p R$ truncated. The prototype Tn1722-based transposon as observed in pKP048 has a linear structure $\quad \Delta m c p-\mathrm{Tn} 3-\mathrm{ISKpn27-bla} \mathrm{KPC}_{2}-\Delta \mathrm{ISKpn6-korC-klcA-}$ unkown ORF- $\Delta r e p B-\operatorname{Tn} 1722$. Various truncations within the $5^{\prime}$ terminal $\Delta m c p$-Tn3 region can be identified for different KPC-encoding plasmids from China; in p628-KPC, a truncation within $\Delta m c p$-Tn3 leaves only a 402 bp remnant of the $\operatorname{Tn} 3 \operatorname{tn} p R$ gene at the $5^{\prime}$ end of Tn1722-based transposon. Interestingly, an IS26-based composite transposon, which is almost identical to the counterpart in pHK23 (recovered from pig-derived $E$. coli in China) and harbors the fosfomycin resistance gene fos $A 3$ (Ho et al., 2013a), is inserted into the $\operatorname{tnpRA}$ locus of Tn1722 in
pHS102707, leaving $\operatorname{tn} p R$ and $\operatorname{tn} p A$ truncated. The IS26-based

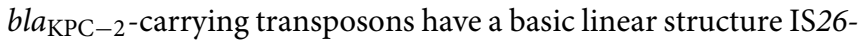

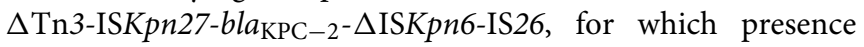
of two IS26 elements at both ends truncates ISKpn6 and Tn3; notably, different lengths of truncated ISKpn 6 can be observed for these IS26-based transposons from different plasmids.

\section{Genetic Surroundings of bla}

R64, p628-CTXM, pKHSB1, and pEK204 carry a 17 kb IS2-based mobile element, a 2980 bp ISEcp1-based transposition unit, a 7935 bp Tn3-based element, and an 8014 bp Tn3-based element respectively; each of them is the sole determinant for antibiotics resistance of the corresponding plasmid (Figure 4). For R64, stepwise insertions occur to eventually assemble the IS2-based element: insertion of IS2 into $\operatorname{ars} A 1$, that of Tn6082 into IS2, that of IS1133 into Tn6082, and finally that of Tn10 into IS1133; the tet locus carried by $\operatorname{Tn} 10$ and the $\operatorname{str} A B$ operon carried by Tn6082 account for resistance to tetracycline and streptomycin respectively.

A lot of bla $a_{\mathrm{CTX}-\mathrm{M}-1}$ group genes such as bla $a_{\mathrm{CTX}-\mathrm{M}-55}$, $b l a_{\mathrm{CTX}-\mathrm{M}-15}$ and $b l a_{\mathrm{CTX}-\mathrm{M}-3}$ are often connected with ISEcp1 (upstream; responsible for capture and mobilization of bla $_{\mathrm{CTX}-\mathrm{M}}$ ) and $\Delta$ orf477 (downstream), constituting an ISEcp1-bla ${ }_{\mathrm{CTX}-\mathrm{M}}-\Delta$ orf 477 transposition unit (Lartigue et al., 
$\mathbf{P 2}^{\text {ISKpn } 7}$

ISKpn $7 \stackrel{-\mathbf{3 5}}{\text { (2) }}$

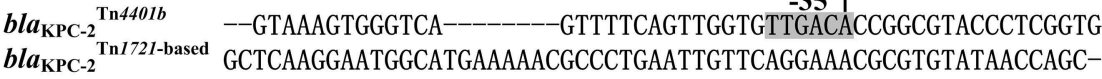

$* * * * * * \quad * \quad * * * * * * \quad * * * * \quad * * * * \quad * *$ $\mathbf{P} 2^{\operatorname{ISKpn} 7}$

$-10 \longrightarrow$ Transcription start

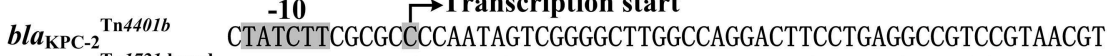

bla $_{\text {KPC-2 }}$ Tn1721-based --_---CGGGTCTTGACATATAGGTTAATGTCATGA--TAATAATGGTTTCTTAGACGT

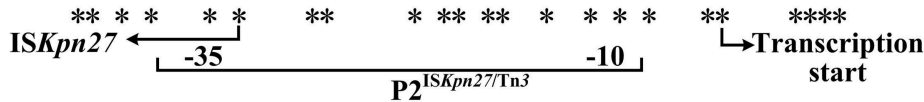

$\begin{array}{ll}\text { bla }_{\text {KPC-2 }}^{\text {Tn4401b }} & \text {-GGATGCCGAGGTCAGGCGAGGTGGCCGACCCATGAACGCCGACCTGATTCGTTTTTC-- } \\ \text { bla }_{\text {KPC-2 }} & \text { CAGGTGGCACTTTTCGGGGAAATGTGCG---CG-GAACCCCTATTTG-TTTATTTTTCTA }\end{array}$

$* * * * \quad * \quad * * * * \quad * * \quad * * \quad * \quad * * * * * * * \quad * * * * \quad * * * * * *$

bla $_{\text {KPC-2 }}^{\text {Tn4401b }}$ AATAGCGCTGGACGTTGTGGT-GCCAGGGACTTACCAACCC-GATGTGTGCCCATCCGGG

bla $_{\text {KPC-2 }}$ Tn1721-based AATA-CATTCAAATATGTATCCGCTCATGAGACAATAACCCTGATAAATGCT--TCAATA

$* * * * * * \quad * \quad * * * \quad * * \quad * * \quad * \quad * * * * * * * * \quad * * * \quad * *$

bla $_{\text {KPC-2 }}^{\text {Tn } 4 \text { 401b }}$ GCAGTTACAGCCGTTACAGCCTCTGGAGAGGGAGCGGCTTGCCGCTCGGTGA-

bla $_{\text {KPC-2 }}{ }^{\text {Tn } 1721 \text {-based }}$ ATATTGAAAA-----ATGACTTCTTAACGTGAGTTTTCGTTCCACTGAGCGTCAGACCCC

$* * * * \quad * \quad * * * * \quad * \quad * \quad * * * * * * \quad * * \quad \operatorname{Tn} 3$

P1

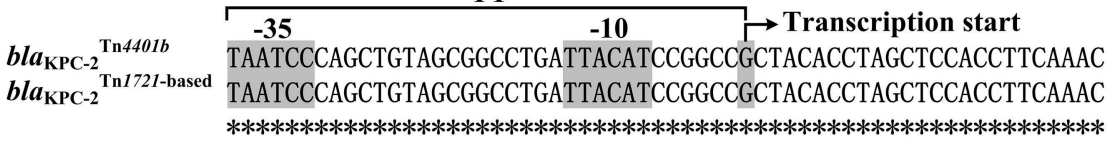

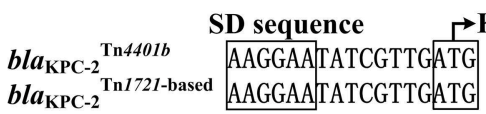

$* * * * * * * * * * * * * * * * * *$

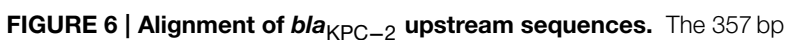
upstream sequences together with the start codon of the bla $\mathrm{KPC}_{2}$ genes were aligned by CLUSTALW (http://clustalw.ddbj.nig.ac.jp/). Shown were core promoter regions, -35 and -10 elements, transcription starts, Shine-Dalgarno (SD) sequences for ribosome recognition, and translation starts. Asterisks indicate the identical nucleotides.
2006; Zong et al., 2010). In p628-KPC, the plasmid backbone

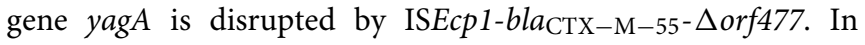
pKHSB1 and pEK204, a bla $a_{T E M-1}$-carrying Tn3 transposon is inserted at the site downstream of $y a g A$ and the $\operatorname{Tn} 3 \operatorname{tnp} A$

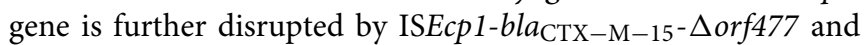

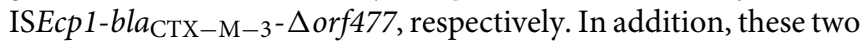
inserted ISEcp1-based structures differ from each other with respect to targeting sites and oriented directions (Figure 4).

\section{Expression of bla $\mathrm{KPC}-2_{2}$ and bla $a_{\mathrm{CTX}-\mathrm{M}-55}$}

Each of the $b l a_{\mathrm{KPC}-2}$ genes in $\operatorname{Tn} 4401 a, b, d, f$, and $g$ has two transcription starts, i.e., nucleotides $\mathrm{G}$ and $\mathrm{C}$ located at 39 and $289 \mathrm{bp}$ upstream of $b l a_{\mathrm{KPC}-2}$, which correspond to the two promoters $\mathrm{P} 1$ and $\mathrm{P} 2$ (re-designated $\mathrm{P} 2^{I S K p n 7}$ herein) with core -35/-10 elements TAATCC/TTACAT and TTGACA/TATCTT respectively (Naas et al., 2012). By contrast, bla $a_{\mathrm{KPC}-2}$ from Tn4401c or $e$ has only $\mathrm{P} 1$, while $\mathrm{P} 2^{I S K p n 7}$ is absent due to presence of 215 or $255 \mathrm{bp}$ deletion within $b l a_{\mathrm{KPC}-2}$ upstream region respectively (Naas et al., 2012).

In this work, the primer extension assay detected two transcription starts, i.e., nucleotides $\mathrm{G}$ and $\mathrm{C}$ located at 39 and $250 \mathrm{bp}$ upstream of bla $a_{\mathrm{KPC}-2}$ Tn1722-based from p628-KPC respectively; the corresponding two promoters were designated $\mathrm{P} 1$ and $\mathrm{P} 2^{I S K p n 27 / T n 3}$ with the core $-35 /-10$ elements TAATCC/TTACAT and TTGACA/AATAAT respectively (Figures 5, 6). The first $74 \mathrm{bp}$ fragments upstream of $b l a_{\mathrm{KPC}-2}{ }^{\text {Tn } 4401 b}$ and $b l a_{\mathrm{KPC}-2}{ }^{\text {Tn1722-based }}$ are essentially identical; the P1 promoter is located within this $74 \mathrm{bp}$ region and thereby shared by $b l a_{\mathrm{KPC}-2}{ }^{\mathrm{Tn} 4401 b}$ and $b l a_{\mathrm{KPC}-2}$ Tn1722-based (Figure 6). The next $280 \mathrm{bp}$ region upstream of the above $74 \mathrm{bp}$ fragment for $b l a_{\mathrm{KPC}-2}{ }^{\mathrm{Tn} 4401 b}$ is dramatically divergent at nucleotide level from the counterpart

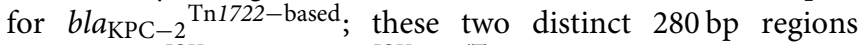
contain $\mathrm{P} 2^{\mathrm{ISKp} n 7}$ and $\mathrm{P} 2^{\mathrm{ISKpn} 27 / \mathrm{Tn} 3}$ respectively. The -35 element of $\mathrm{P} 2^{I S K p n 7}$ is provided by ISKpn7 inserted at $319 \mathrm{bp}$ upstream of $b l a_{\mathrm{KPC}-2}{ }^{\mathrm{Tn} 4401 b}$, while the -35 and -10 elements of $\mathrm{P} 2^{\mathrm{ISKp} n 27 / \mathrm{Tn} 3}$ are provided by ISKpn27 and Tn3 inserted at 281 and $75 \mathrm{bp}$ upstream of bla $a_{\mathrm{KPC}-2}$ Tn1722-based respectively (Figure 6).

Spacer regions between ISEcp1 and $b \operatorname{la}_{\mathrm{CTX}-\mathrm{M}-55}$ from different ISEcp1-bla $a_{\mathrm{CTX}-\mathrm{M}-55}$ isoforms display three different

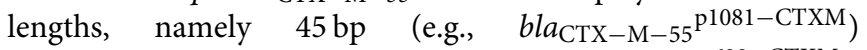
$\left(\mathrm{Qu}\right.$ et al., 2014), $48 \mathrm{bp}$ (e.g. $\left.\quad b a_{\mathrm{CTX}-\mathrm{M}-55}{ }^{\mathrm{p} 628-\mathrm{CTXM}}\right)$,

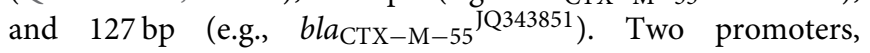
TTGAAA-N 18 -TACAAT-N 6 -G (organized as -35 element/-10 element/transcription start; named $\mathrm{P} 1)$ and TTGACT-N 18 -TTTCGT-N 6 -C (P2), are experimentally identified for $b l a_{\mathrm{CTX}-\mathrm{M}-3}{ }^{\mathrm{AF} 550415}$ with a $127 \mathrm{bp}$ spacer and 
P1

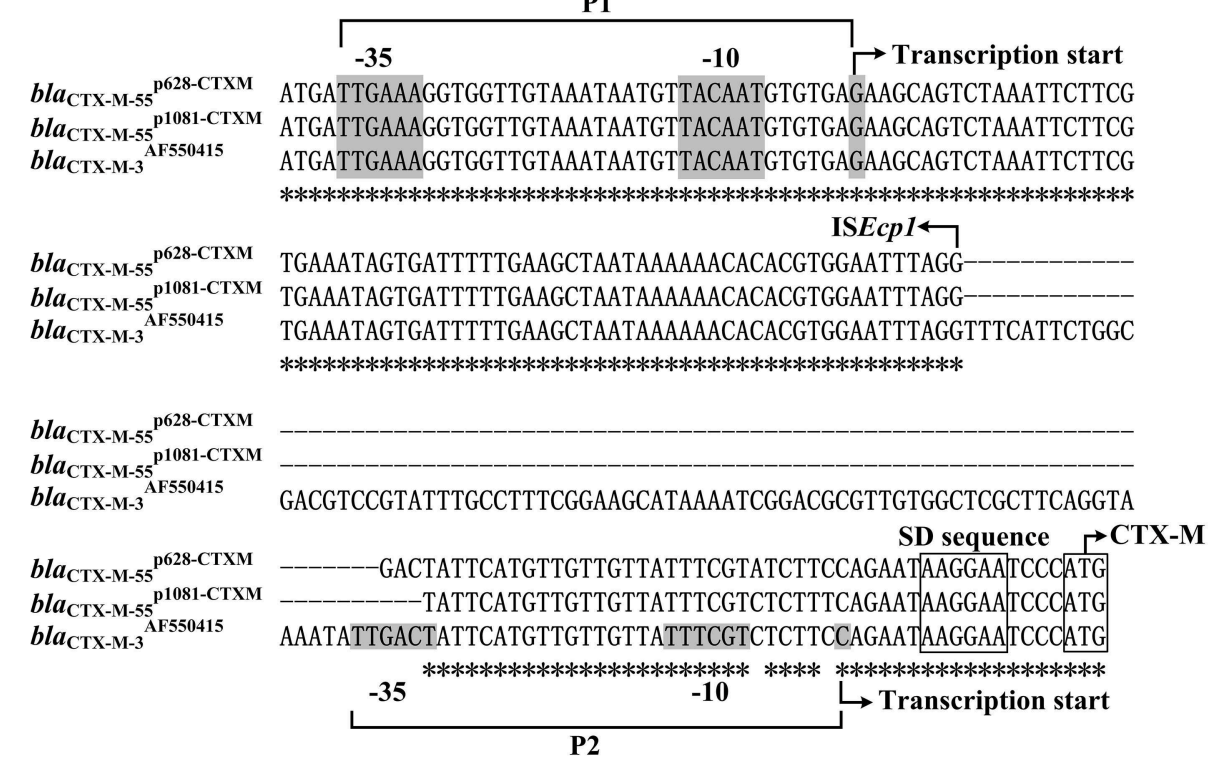

FIGURE 7 | Alignment of bla ${ }_{\mathrm{CTX}-\mathrm{M}}$ upstream sequences. The 153-235 bp upstream sequences together with the start codon of the bla $\mathrm{CTX}-\mathrm{M}$ genes were aligned by CLUSTALW. Shown were core promoter regions, -35 and -10 elements, transcription starts, SD sequences for ribosome recognition, and translation starts. Asterisks indicate the identical nucleotides moreover, the ISEcp1-provided promoter P1 is stronger and more important than the intrinsic P2 promoter in the $127 \mathrm{bp}$ spacer (Ma et al., 2011). The above result is applicable to the bla $a_{\mathrm{CTX}-\mathrm{M}-55}$ genes with the $127 \mathrm{bp}$ spacer (Figure 7), because their ISEcp1+spacer region is identical to the counterpart of bla $_{\mathrm{CTX}-\mathrm{M}-3}{ }^{\mathrm{AF} 550415}$.

In the present study, the primer extension assays detected a transcription start, i.e., nucleotides $\mathrm{G}$ located at $116 \mathrm{bp}$ upstream of bla $a_{\mathrm{CTX}-\mathrm{M}-55}$ (Figure 5), which corresponded to the P1

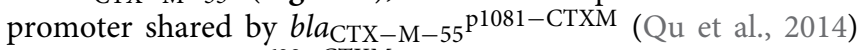

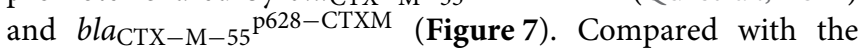
$127 \mathrm{bp}$ spacer, the 45 or $48 \mathrm{bp}$ spacer for bla $_{\mathrm{CTX}-\mathrm{M}-55}{ }^{\mathrm{p} 1081-\mathrm{CTXM}}$

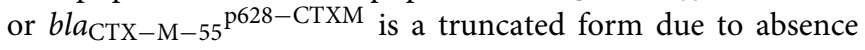
of a 82 or $79 \mathrm{bp}$ region respectively. The deletion event impairs the -35 element of P2, most likely making the

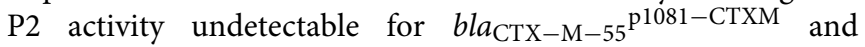

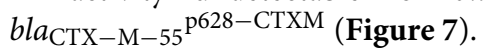

In addition, the primer extension assay showed that addition of increasing amounts of imipenem or ampicillin during cultivation of indicated strains 628, 628-KPC-EC600 and 628CTXM-EC600 had no effect on activity of all the above promoters detected for $b l a_{\mathrm{KPC}-2}$ or $b l a_{\mathrm{CTX}-\mathrm{M}-55}$, denoting constitutive expression of the above two resistance genes (Figure 5).

\section{Concluding Remarks}

KPC-2 and CTX-M-55 enzymes are produced by two different conjugative plasmids, p628-KPC and p628-CTXM respectively, in $K$. pneumoniae strain 628 , and the sequences of these two plasmids are $>98 \%$ identical to other relevant plasmids carrying the same resistance determinants previously sequenced. The detected bla $a_{\mathrm{KPC}-2}$ gene is captured by a Tn1722-based unit transposon carried by an IncFII $_{K}$-type multi-drugresistant plasmid p628-KPC, and this gene has two different promoters, the intrinsic P1 and the ISKpn27/Tn3-provided $\mathrm{P} 2$, both characteristic of constitutive expression. The detected bla $a_{\mathrm{CTX}-\mathrm{M}-55}$ gene, being the sole drug-resistant determinant in the plasmid, is mobilized in an ISEcp1-based transposition unit carried by an IncI1 plasmid p628-CTXM, and this gene has a single ISEcp1-provided promoter driving bla $a_{\mathrm{CTX}-\mathrm{M}-55}$ expression in a constitutive manner. Coexistence of $b l a_{\mathrm{KPC}}$ and bla $a_{\mathrm{CTX}-\mathrm{M}}$ in $\mathrm{K}$. pneumoniae has been reported many times, but this is the first report to gain deep insights into genetic platforms, promoters, and expression of the two coexisted bla genes. The IncFII $_{K}$ and IncI1 plasmids have been frequently identified to carry horizontally acquired drug-resistant gene modules and could be transmitted across a number of bacterial species (Woodford et al., 2009; Jiang et al., 2010; Sampei et al., 2010; Holt et al., 2013), and increased surveillance of these drug-resistant plasmids is needed.

\section{Funding}

This work is funded by National High-Tech Research and Development Program (2014AA021402), National Key Program for Infectious Disease of China (2013ZX10004216), and National Natural Science Foundation of China (31471184 and 31170127).

\section{Supplementary Material}

The Supplementary Material for this article can be found online at: http://journal.frontiersin.org/article/10.3389/fmicb. 2015.00838 


\section{References}

Bryant, K. A., Van Schooneveld, T. C., Thapa, I., Bastola, D., Williams, L. O., Safranek, T. J., et al. (2013). KPC-4 Is encoded within a truncated Tn4401 in an IncL/M plasmid, pNE1280, isolated from Enterobacter cloacae and Serratia marcescens. Antimicrob. Agents Chemother. 57, 37-41. doi: 10.1128/AAC.01062-12

Cai, J. C., Zhou, H. W., Zhang, R., and Chen, G. X. (2008). Emergence of Serratia marcescens, Klebsiella pneumoniae, and Escherichia coli isolates possessing the plasmid-mediated carbapenem-hydrolyzing beta-lactamase KPC-2 in intensive care units of a Chinese hospital. Antimicrob. Agents Chemother. 52, 2014-2018. doi: 10.1128/AAC.01539-07

Chen, L., Chavda, K. D., Mediavilla, J. R., Jacobs, M. R., Levi, M. H., Bonomo, R. A., et al. (2012). Partial excision of blaKPC from Tn4401 in Carbapenemresistant Klebsiella pneumoniae. Antimicrob. Agents Chemother. 56, 1635-1638. doi: 10.1128/AAC.06182-11

Chen, L., Hu, H., Chavda, K. D., Zhao, S., Liu, R., Liang, H., et al. (2014a). Complete sequence of a KPC-producing IncN multidrug-resistant plasmid from an epidemic Escherichia coli sequence type 131 strain in China. Antimicrob. Agents Chemother. 58, 2422-2425. doi: 10.1128/AAC.02587-13

Chen, Y. T., Lin, J. C., Fung, C. P., Lu, P. L., Chuang, Y. C., Wu, T. L., et al. (2014b), KPC-2-encoding plasmids from Escherichia coli and Klebsiella pneumoniae in Taiwan. J. Antimicrob. Chemother. 69, 628-631. doi: 10.1093/jac/dkt409

Chen, Z., Li, H., Feng, J., Li, Y., Chen, X., Guo, X., et al. (2015). NDM-1 encoded by a pNDM-BJ01-like plasmid p3SP-NDM in clinical Enterobacter aerogenes. Front. Microbiol. 6:294. doi: 10.3389/fmicb.2015.00294

Chmelnitsky, I., Shklyar, M., Leavitt, A., Sadovsky, E., Navon-Venezia, S., Ben Dalak, M., et al. (2014). Mix and match of KPC-2 encoding plasmids in Enterobacteriaceae-comparative genomics. Diagn. Microbiol. Infect. Dis. 79, 255-260. doi: 10.1016/j.diagmicrobio.2014.03.008

CLSI (2012). Performance Standards for Antimicrobial Susceptibility Testing: Twenty-Second Informational Supplement M10-S22. Wayne, PA: CLSI.

Cuzon, G., Naas, T., Villegas, M. V., Correa, A., Quinn, J. P., and Nordmann, P. (2011). Wide dissemination of Pseudomonas aeruginosa producing betalactamase bla $a_{\mathrm{KPC}-2}$ gene in Colombia. Antimicrob. Agents Chemother. 55, 5350-5353. doi: 10.1128/AAC.00297-11

Frank, J. A., Reich, C. I., Sharma, S., Weisbaum, J. S., Wilson, B. A., and Olsen, G. J. (2008). Critical evaluation of two primers commonly used for amplification of bacterial 16S rRNA genes. Appl. Environ. Microbiol. 74, 2461-2470. doi: 10.1128/AEM.02272-07

Ho, P. L., Chan, J., Lo, W. U., Law, P. Y., and Chow, K. H. (2013a). Plasmidmediated fosfomycin resistance in Escherichia coli isolated from pig. Vet. Microbiol. 162, 964-967. doi: 10.1016/j.vetmic.2012.09.023

Ho, P. L., Cheung, Y. Y., Lo, W. U., Li, Z., Chow, K. H., Lin, C. H., et al. (2013b). Molecular characterization of an atypical IncX3 Plasmid pKPC-NY79 carrying bla KPC-2 in a Klebsiella pneumoniae. Curr. Microbiol. 67, 493-498. doi: 10.1007/s00284-013-0398-2

Holt, K. E., Thieu Nga, T. V., Thanh, D. P., Vinh, H., Kim, D. W., Vu Tra, M. P., et al. (2013). Tracking the establishment of local endemic populations of an emergent enteric pathogen. Proc. Natl. Acad. Sci. U.S.A. 110, 17522-17527. doi: 10.1073/pnas.1308632110

Jiang, Y., Yu, D., Wei, Z., Shen, P., Zhou, Z., and Yu, Y. (2010). Complete nucleotide sequence of Klebsiella pneumoniae multidrug resistance plasmid pKP048, carrying blaKPC-2, blaDHA-1, qnrB4, and armA. Antimicrob. Agents Chemother. 54, 3967-3969. doi: 10.1128/AAC.00137-10

Kitchel, B., Rasheed, J. K., Endimiani, A., Hujer, A. M., Anderson, K. F., Bonomo, R. A., et al. (2010). Genetic factors associated with elevated carbapenem resistance in KPC-producing Klebsiella pneumoniae. Antimicrob. Agents Chemother. 54, 4201-4207. doi: 10.1128/AAC.00008-10

Kitchel, B., Rasheed, J. K., Patel, J. B., Srinivasan, A., Navon-Venezia, S., Carmeli, Y., et al. (2009). Molecular epidemiology of KPC-producing Klebsiella pneumoniae isolates in the United States: clonal expansion of multilocus sequence type 258. Antimicrob. Agents Chemother. 53, 3365-3370. doi: 10.1128/AAC.00126-09

Lartigue, M. F., Poirel, L., Aubert, D., and Nordmann, P. (2006). In vitro analysis of ISEcp1B-mediated mobilization of naturally occurring beta-lactamase gene blaCTX-M of Kluyvera ascorbata. Antimicrob. Agents Chemother. 50, 1282-1286. doi: 10.1128/AAC.50.4.1282-1286.2006
Leavitt, A., Carmeli, Y., Chmelnitsky, I., Goren, M. G., Ofek, I., and NavonVenezia, S. (2010). Molecular epidemiology, sequence types, and plasmid analyses of KPC-producing Klebsiella pneumoniae strains in Israel. Antimicrob. Agents Chemother. 54, 3002-3006. doi: 10.1128/AAC.01818-09

Leavitt, A., Navon-Venezia, S., Chmelnitsky, I., Schwaber, M. J., and Carmeli, Y. (2007). Emergence of KPC-2 and KPC-3 in carbapenem-resistant Klebsiella pneumoniae strains in an Israeli hospital. Antimicrob. Agents Chemother. 51, 3026-3029. doi: 10.1128/AAC.00299-07

Li, G., Wei, Q., Wang, Y., Du, X., Zhao, Y., and Jiang, X. (2011). Novel genetic environment of the plasmid-mediated KPC-3 gene detected in Escherichia coli and Citrobacter freundii isolates from China. Eur. J. Clin. Microbiol. Infect. Dis. 30, 575-580. doi: 10.1007/s10096-010-1124-7

Li, G., Zhang, Y., Bi, D., Shen, P., Ai, F., Liu, H., et al. (2015). First report of a clinical, multidrug-resistant Enterobacteriaceae isolate coharboring fosfomycin resistance gene fosA 3 and carbapenemase gene $b l a_{\mathrm{KPC}-2}$ on the same transposon, Tn1721. Antimicrob. Agents Chemother. 59, 338-343. doi: 10.1128/AAC.03061-14

Ma, L., Siu, L. K., and Lu, P. L. (2011). Effect of spacer sequences between bla(CTXM) and ISEcp1 on bla(CTX-M) expression. J. Med. Microbiol. 60, 1787-1792. doi: 10.1099/jmm.0.033910-0

Munoz-Price, L. S., Poirel, L., Bonomo, R. A., Schwaber, M. J., Daikos, G. L., Cormican, M., et al. (2013). Clinical epidemiology of the global expansion of Klebsiella pneumoniae carbapenemases. Lancet Infect. Dis. 13, 785-796. doi: 10.1016/S1473-3099(13)70190-7

Naas, T., Bonnin, R. A., Cuzon, G., Villegas, M. V., and Nordmann, P. (2013). Complete sequence of two KPC-harbouring plasmids from Pseudomonas aeruginosa. J. Antimicrob. Chemother. 68, 1757-1762. doi: 10.1093/jac/ dkt094

Naas, T., Cuzon, G., Truong, H. V., and Nordmann, P. (2012). Role of ISKpn7 and deletions in blaKPC gene expression. Antimicrob. Agents Chemother. 56, 4753-4759. doi: 10.1128/AAC.00334-12

Naas, T., Cuzon, G., Villegas, M. V., Lartigue, M. F., Quinn, J. P., and Nordmann, P. (2008). Genetic structures at the origin of acquisition of the betalactamase bla KPC gene. Antimicrob. Agents Chemother. 52, 1257-1263. doi: 10.1128/AAC.01451-07

Peirano, G., Seki, L. M., Val Passos, V. L., Pinto, M. C., Guerra, L. R., and Asensi, M. D. (2009). Carbapenem-hydrolysing beta-lactamase KPC-2 in Klebsiella pneumoniae isolated in Rio de Janeiro, Brazil. J. Antimicrob. Chemother. 63, 265-268. doi: 10.1093/jac/dkn484

Pérez-Chaparro, P. J., Cerdeira, L. T., Queiroz, M. G., De Lima, C. P., Levy, C. E., Pavez, M., et al. (2014). Complete nucleotide sequences of two blaKPC-2bearing IncN Plasmids isolated from sequence type 442 Klebsiella pneumoniae clinical strains four years apart. Antimicrob. Agents Chemother. 58, 2958-2960. doi: 10.1128/AAC.02341-13

Qu, F., Ying, Z., Zhang, C., Chen, Z., Chen, S., Cui, E., et al. (2014). Plasmid-encoding extended-spectrum beta-lactamase CTX-M-55 in a clinical Shigella sonnei strain, China. Future Microbiol. 9, 1143-1150. doi: 10.2217/ fmb. 14.53

Roberts, A. P., Chandler, M., Courvalin, P., Guédon, G., Mullany, P., Pembroke, T., et al. (2008). Revised nomenclature for transposable genetic elements. Plasmid 60, 167-173. doi: 10.1016/j.plasmid.2008.08.001

Sampei, G., Furuya, N., Tachibana, K., Saitou, Y., Suzuki, T., Mizobuchi, K., et al. (2010). Complete genome sequence of the incompatibility group I1 plasmid R64. Plasmid 64, 92-103. doi: 10.1016/j.plasmid.2010.05.005

Shen, P., Wei, Z., Jiang, Y., Du, X., Ji, S., Yu, Y., et al. (2009). Novel genetic environment of the carbapenem-hydrolyzing beta-lactamase KPC-2 among Enterobacteriaceae in China. Antimicrob. Agents Chemother. 53, 4333-4338. doi: 10.1128/AAC.00260-09

Siguier, P., Perochon, J., Lestrade, L., Mahillon, J., and Chandler, M. (2006). ISfinder: the reference centre for bacterial insertion sequences. Nucleic Acids Res. 34, D32-D36. doi: 10.1093/nar/gkj014

Souli, M., Galani, I., Antoniadou, A., Papadomichelakis, E., Poulakou, G., Panagea, T., et al. (2010). An outbreak of infection due to beta-Lactamase Klebsiella pneumoniae Carbapenemase 2-producing K. pneumoniae in a Greek University Hospital: molecular characterization, epidemiology, and outcomes. Clin. Infect. Dis. 50, 364-373. doi: $10.1086 / 649865$

Tzouvelekis, L. S., Markogiannakis, A., Psichogiou, M., Tassios, P. T., and Daikos, G. L. (2012). Carbapenemases in Klebsiella pneumoniae and other 
Enterobacteriaceae: an evolving crisis of global dimensions. Clin. Microbiol. Rev. 25, 682-707. doi: 10.1128/CMR.05035-11

Woodford, N., Carattoli, A., Karisik, E., Underwood, A., Ellington, M. J., and Livermore, D. M. (2009). Complete nucleotide sequences of plasmids pEK204, pEK499, and pEK516, encoding CTX-M enzymes in three major Escherichia coli lineages from the United Kingdom, all belonging to the international O25:H4-ST131 clone. Antimicrob. Agents Chemother. 53, 4472-4482. doi: 10.1128/AAC.00688-09

Zhang, Y., Gao, H., Wang, L., Xiao, X., Tan, Y., Guo, Z., et al. (2011). Molecular characterization of transcriptional regulation of rovA by PhoP and RovA in Yersinia pestis. PLoS ONE 6:e25484. doi: 10.1371/journal.pone. 0025484

Zong, Z., Partridge, S. R., and Iredell, J. R. (2010). ISEcp1-mediated transposition and homologous recombination can explain the context of bla(CTX-M-62) linked to qnrB2. Antimicrob. Agents Chemother. 54, 3039-3042. doi: 10.1128/AAC.00041-10

Conflict of Interest Statement: The authors declare that the research was conducted in the absence of any commercial or financial relationships that could be construed as a potential conflict of interest.

Copyright (c) 2015 Wang, Fang, Feng, Yin, Xie, Zhu, Wang, Chen, Yang, Du and Zhou. This is an open-access article distributed under the terms of the Creative Commons Attribution License (CC BY). The use, distribution or reproduction in other forums is permitted, provided the original author(s) or licensor are credited and that the original publication in this journal is cited, in accordance with accepted academic practice. No use, distribution or reproduction is permitted which does not comply with these terms. 